\title{
EL MUSEO FUERA DEL MUSEO. UN NUEVO CONCEPTO TERRITORIAL Y RELACIONAL PARA EL MUSEO DEL MAR DE SANTA POLA Y SU MARCA DESTINO
}

\author{
María José Cerdá Bertoméu* \\ Susana H. Soler Beresaluze \\ Guillermo Pérez Sansano ${ }^{* * *}$
}

\section{RESUMEN}

Santa Pola (Costa Blanca, Alicante, España) es un clásico destino maduro que fundamentó su oferta en el turismo residencial de sol y playa. Ante la necesidad de mantener su promesa de valor y complementar y diversificar su oferta, en el presente artículo se exploran posibilidades y experiencias basadas en el turismo patrimonial. Para ello, se propone un nuevo modelo de gestión del patrimonio local (cultural y natural) desde la filosofía del territorio-museo a desarrollar por el Museo del Mar, como museo oficial reconocido en la red valenciana de museos. En ese marco, se plantea que los museos deben ser verdaderos agentes turísticos enfocados a la conservación del patrimonio, la creación de experiencias turístico-patrimoniales, la potenciación de la imagen del destino y el desarrollo territorial.

Palabras Clave: turismo, cultura, museo, Santa Pola, patrimonio.

\section{THE MUSEUM OUTSIDE THE MUSEUM. A NEW TERRITORIAL AND RELATIONAL CONCEPT FOR THE SANTA POLA SEA MUSEUM AND ITS DESTINATION BRAND}

\section{Abstract}

Santa Pola (Costa Blanca, Alicante, Spain) is a classic, mature destination, and a popular choice for residential sun and beach holidays. Faced with the need to maintain its value promise and add to and diversify its product, this article explores opportunities and experiences based on heritage tourism. To achieve this, we propose a new way of managing local heritage (cultural and natural) based on a territorial-museum philosophy to be developed by the Museum of the Sea, as an official museum that forms part of the Valencia region's museum network. In this framework, it is suggested that museums should be authentic tourism agents, focused on conserving heritage, creating heritage-tourism experiences, enhancing the destination's image and territorial development.

KEYwORds: tourism, culture, museum, Santa Pola, heritage. 


\section{INTRODUCCIÓN}

El presente trabajo centra su estudio en el caso de un municipio turístico de la Costa Blanca española, Santa Pola, que atiende a los aspectos clásicos de un destino maduro que basó su modelo en el turismo residencial. En la actualidad, Santa Pola está repensando su modelo turístico y de ciudad a partir de diferentes planes estratégicos para el territorio y el destino. Santa Pola, como otros municipios de la Costa Blanca, se enfrenta al reto de reposicionar su oferta turística mediante una estrategia de diversificación de producto, que complemente la actual oferta basada en el mar desde un punto de vista balnerario y deportivo-recreativo. Para ello, en este trabajo se han analizado las propuestas realizadas por los Planes Estratégicos precedentes y en curso y los diferentes activos ociosos del territorio, encontrando que en sus activos patrimoniales (culturales y naturales) existe un gran potencial para el desarrollo de productos turísticos. Como una de las áreas de actuación prioritaria, la investigación apunta a que este enfoque requiere de un nuevo modelo de gestión del patrimonio, más multidisciplinar y holístico, plasmado en un novedoso Plan Museológico aprobado por unanimidad del Pleno del Ayuntamiento. El valor de este documento rebasa las particularidades locales al constituirse como la primera propuesta que un museo local alicantino realiza desde el enfoque de museo-territorio, pudiendo ser, este documento, instrumento de consulta para académicos y para que otros museos emprendan un camino que exceda el estricto ámbito cultural y desarrollen su actividad enfocados hacia el desarrollo e innovación de sus territorios. Este texto posee una vocación clara hacia la gestión al plantear un nuevo enfoque en la estrategia de oferta del destino. La descripción y reflexión sobre el destino y la definición y descripción de conceptos novedosos de gestión resulta clave para una mejor comprensión de la propuesta planteada, que incide en un modelo concreto para presentar, gestionar y comunicar la oferta turístico-cultural local. Este texto no pretende poner el foco en el destino desde el punto de vista de la demanda. Analizar la imagen en la mente del destino o el valor de marca otorgado por los usuarios de la marca turística es, sin duda, fundamental, pero objeto de otra investigación distinta y necesaria y que, por tanto, se abordará en futuras investigaciones. Con el fin de clarificar el enfoque propuesto para la creación, gestión y comunicación desde una perspectiva de la oferta, en este documento se han plasmado las principales contribuciones teóricas sobre los destinos maduros litorales mediterráneos, las aportaciones de los planes estratégicos precedentes para el destino, los nuevos

* Directora de Museos y Patrimonio Histórico del Ayuntamiento de Santa Pola (Alicante). Investigadora del Instituto Mediterráneo de Estudios de Protocolo, Centro Adscrito Universidad Miguel Hernández. E-mail: mjcerda@protocoloimep.com.

** Desarrollo de proyectos museográficos y contenidos documentales en Rocamora Diseño Arquitectura SLP.E-mail: susana@rocamoraarquitectura.com.

*** Desarrollo de proyectos museográficos y contenidos documentales en Rocamora Diseño y Arquitectura SLP. E-mail: proyectos5@rocamoraarquitectura.com. 
modelos de gestión turístico-cultural y su aplicación para el diseño de la oferta y su comunicación estratégica del destino Santa Pola.

\section{El PAPEl del PATRIMONIO EN LA CONFIGURACIÓN DE LOS DESTINOS LITORALES MEDITERRÁNEOS ESPAÑOLES}

Entendemos una marca destino como una promesa de valor distintiva, relevante y memorable de una experiencia de viaje asociada a un lugar, cuya finalidad es facilitar la identificación y el reconocimiento del destino, reducir los costes de riesgo percibido ante la potencial elección de compra y generar un vínculo emocional entre el visitante y el territorio (Blain, Levy y Ritchie, 2005; Kerr, 2006). No existe un consenso generalizado de cómo se crea o reposiciona un destino. Básicamente conviven dos visiones, en la primera de ellas se plantea que un destino se forja desde la creación de experiencias turísticas. Encontramos aquí un enfoque marketiniano clásico en el que se defiende que si no se oferta un producto turístico bien estructurado, comercializado y comunicado, no existe destino entendido como un modelo de negocio socioeconómico, para un territorio, con un enfoque claro (Baker, 2012). Según esta visión, una marca destino se desarrolla a partir de la oferta, estructura de unos productos de marca en diálogo entre sí o, al menos, con carencia de conflicto en su oferta y capaces de representar los atributos más relevantes de la realidad de la marca. Una segunda visión apunta a que un destino turístico se estructura básicamente en torno a un relato, a una narrativa común que aglutina los principales acontecimientos, expresiones e instituciones que se dan en el territorio. Esta perspectiva, desde el marketing y la comunicación de destinos, corresponde a una visión predominantemente posmoderna, donde la imagen y las percepciones de los públicos son fundamentales en la definición de la realidad, actuando como marco de significación de los hechos y las manifestaciones del destino presentes y futuras (Linchrou, O'Malley y Patterson, 2008). Ciertamente, como se va a exponer en las siguientes páginas, productos y experiencias, por un lado, e imagen percibida, por otro, contribuyen a forjar lo que denominamos marca destino en dos direcciones. Desde la marca hacia los públicos, los gestores de la marca han de definir los procesos de gestión y comunicación estratégica de la marca de un destino, es decir, de una comunidad, cuando se presenta hacia el exterior, en las historias que cuenta de sí misma y en los modelos de negocio turístico que ofrece para consumir por los públicos externos. Pero también, desde los públicos, la imagen percibida y la reputación generan unas expectativas hacia la marca en cuanto a sus comportamientos esperados, que influyen per se en la oferta del destino y son cuestiones que se habrán de abordar con sumo conocimiento de las percepciones de los públicos, cuando existan necesidades de reposicionamiento del destino y, por tanto, de un renovado diseńo de la estrategia de marca (Florek y Insch, 2011). Así, desde una perspectiva relacional, parece más enriquecedor concebir que las marcas son fenómenos sociales cocreados entre los gestores de la marca y sus públicos y que, por tanto, en la configuración de la promesa de valor de un destino conviven factores 'duros' ( $h a r d$ factors) y 'blandos' (soft factors). En este sentido, parece interesante la aportación, desde la sociología, 
realizada por Giovanardi (2012), el cual apunta que una marca destino es el resultado de un continuo formado entre factores tangibles e intangibles con profundas interconexiones e inseparabilidad, donde los factores 'duros' tienen implicaciones en aquellos 'blandos' y viceversa. De este modo, es posible hacer convivir una perspectiva sociológica 'funcionalista' con otra 'representacionalista', en la que los factores físicos y simbólicos contribuyen a forjar la marca destino. Así dialogan, según el autor, la 'ciudad de las piedras' y la 'ciudad de las palabras'. Este enfoque es de gran importancia para el presente texto orientado a desarrollar el papel de la gestión del patrimonio y los museos en la configuración de las experiencias-producto y el relato de una marca destino concreta: Santa Pola (Costa Blanca, España).

En los últimos tiempos se ha profundizado en el valor simbólico del patrimonio cultural y natural. El patrimonio cultural tangible e intangible (histórico o natural, producto de la acción del ser humano en un territorio en ambos casos) contiene la fuerza de orquestar la mirada hacia el destino turístico, ofrece ángulos, iconos, representaciones, narrativas e interpretaciones que caracterizan un espacio geográfico, una comunidad y una cultura (San Eugenio, Nogué y Govers, 2017). Protagonizan, en gran medida, 'las postales' del destino (ahora virtuales) que secuestran la mirada espontánea hacia el territorio, siendo los lugares (Muñoz, 2008; San Eugenio, Nogué y Govers, 2017) sobre los que se articula gran parte de la comunicación estratégica digital del destino (web y redes sociales propias de la marca), los buscados digitalmente en la fase previa a la decisión de compra del viaje, y los demandados presencialmente una vez que el turista está en el destino para ser, en la mayoría de los casos, inexorablemente reproducidos digitalmente en nuevas imágenes del destino, que se proyectan compartidas en la comunicación digital de los propios visitantes y de los que se hace eco, habitualmente, el propio destino mediante sus redes sociales. Tanto es así que diversos destinos impelen a sus visitantes y locales hacia la cocreación de imágenes y contenido comunicacional digital, generando acciones concretas de crowdsourcing comunicacional enfocadas a la participación activa de los públicos como embajadores de la marca. En definitiva, a ser sus prosumers.

El patrimonio es, por tanto, un potente escenario simbólico para la creación de imágenes turísticas, deliberada y estratégicamente planificadas, para los gestores de la marca, y de fuerte carga emocional para los usuarios de la marca (visitantes, locales). Imágenes coleccionadas y, una y otra vez, escenificadas en público mediante las redes sociales privadas y compartidas desde las redes públicas del destino, en una suerte de mensaje del 'yo estoy/estuve alli' (Delgado, 2000). En este sentido, la búsqueda de autenticidad en los consumos turísticos y el disfrute de experiencias distintivas posicionan al patrimonio como un activo fundamental para la diversificación de los destinos.

Existe un amplio consenso en la literatura especializada en marcas turísticas sobre la necesidad de potenciar la cultura y el patrimonio local en la estrategia de diferenciación del destino (Kavaratzis y Hatch, 2013). De hecho, Lucarelli (2012) propone que los cinco elementos básicos sobre los que construir la oferta de un destino son 'la historia y herencia' del destino, compuesta por recursos como las efemérides y personajes históricos destacables; 'los artefactos y la configuración espacial del territorio', entre los que se incluyen los equipamientos culturales como 

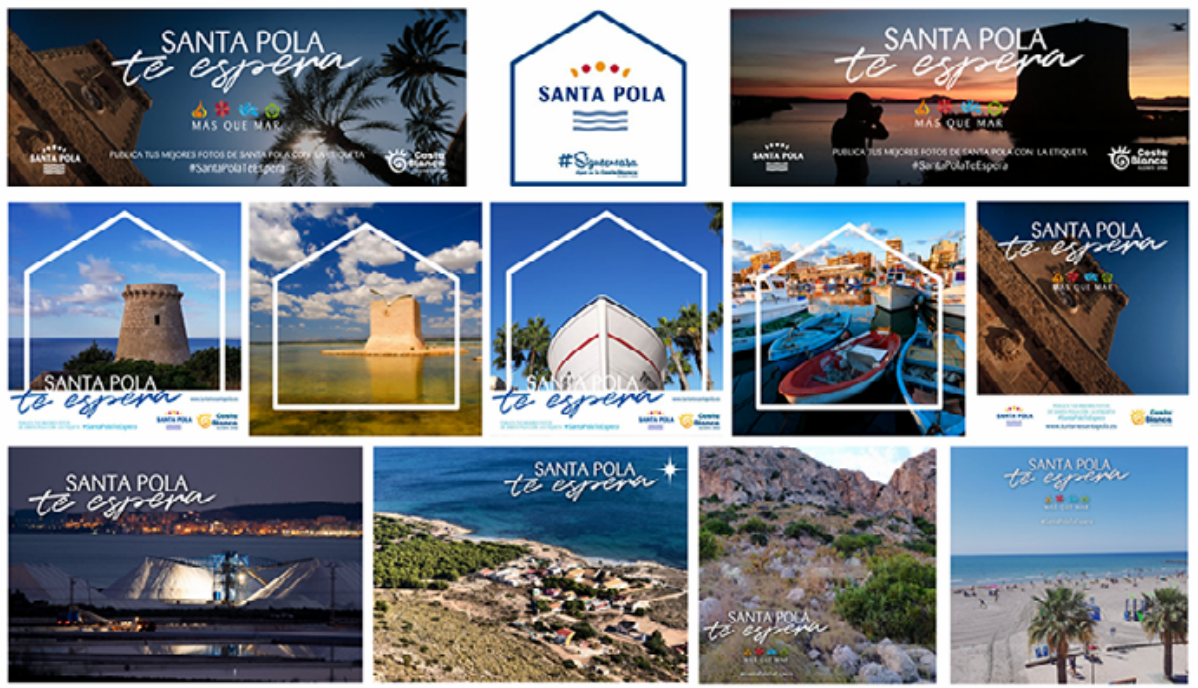

Figura 1. Campaña publicitaria enfocada a la participación activa de los públicos en redes en torno al patrimonio cultural de la marca destino Santa Pola en el contexto covid-19.

Fuente: elaboración propia a partir de Santa Pola Turismo (2020/21).

los museos, el paisaje o las infraestructuras; 'los procesos e instituciones' que implican la generación de un modelo de gestión de la marca turística; 'los grafismos y símbolos' o elementos comunicativos del destino y su arquitectura de marcas (branding); y 'los eventos y actividades' de carácter turístico.

En las sociedades posmodernas, el significado de los vestigios del pasado, en sus vertientes históricas y culturales, es social y cumple funciones sociales y económicas, más allá de las científicas (Rico, 2014). De este modo, se constata cómo el patrimonio posee un importante valor en la conformación de la oferta de productos turísticos del destino y para la construcción de imaginarios en torno a un determinado estilo de vida del lugar. $Y$ esto es así porque cuando un territorio pretende generar o reposicionar estratégicamente una oferta de destino turístico, ha de potenciar determinados elementos de su identidad territorial, seleccionando unos pocos valores y activos distintivos que se convertirán en la base para la construcción de la identidad de marca del destino y de su promesa de valor, facilitando un posicionamiento diferencial en relación con otras ofertas de la competencia (Boisen, Terlouw y Van Gorp, 2011). 
Santa Pola es un destino turístico maduro de la Costa Blanca española, que apostó a partir de los años 60 por un modelo turístico-residencial basado en la oferta de sol y playa, de gran atractivo en las primeras décadas del modelo para el turismo familiar, predominantemente nacional y de clase media-baja. Este binomio turismo-actividad edilicia, sin embargo, y desde un prisma actual, se ha identificado como gran consumidor de recursos limitados, como el suelo o el agua, y altamente homologador. El modelo turístico del litoral alicantino (la Costa Blanca) y, en especial, de Santa Pola responde así, en los orígenes, a un afán desarrollista más que a la planificación estratégica con visión en el largo plazo. Entre los escasos esfuerzos planificadores destacan el Plan de Competitividad Turismo Deportivo Internacional que se desarrolló durante los años 2009-2011 y el actual Plan Director Destino Turístico Inteligente Santa Pola (en proceso de elaboración definitiva).

A esta Santa Pola turística se le une la pesquera, ya que el municipio es también uno de los puertos pesqueros más importantes del Mediterráneo español y europeo, con una de las lonjas más activas y productivas en cuanto a índice de capturas y comercialización del pescado fresco, amparado en la marca de calidad Peix de Santa Pola.

Con el fin de identificar activos (ociosos o con alto potencial de mejora e innovación del producto) que fundamenten una estrategia de diversificación y reposicionamiento para el destino, se presenta un Análisis DAFO fundamentado en las aportaciones precedentes realizadas por el Plan Estratégico de Ciudad SantaPola Avant (2019), el primer informe del Plan Director de Turismo DTI (2020, en curso) y otras cuestiones apuntadas como resultado del proceso investigador llevado a cabo en relación con el Plan Museológico del Museo del Mar recientemente aprobado.

Para que el DAFO anteriormente presentado ayude a formular estrategias posibles para la diversificación y reposicionamiento del destino Santa Pola, a continuación se plantean las estrategias FO (que responden a las fortalezas que nos permitirán aprovechar las oportunidades mejor que la competencia), las estrategias DO (o debilidades a superar para aprovechar mejor las oportunidades), las estrategias FA (o fortalezas para neutralizar amenazas) y las estrategias DA (o debilidades a superar para evitar amenazas).

Varias son las estrategias que un destino litoral maduro del Mediterráneo puede llevar a cabo para evitar el declive de su marca, pero para el caso que nos ocupa, el de Santa Pola, la estrategia de diversificación e innovación parece la más acertada, ya que preserva el modelo turístico con los productos clásicos tractores de los mercados (oferta de sol y playa y oferta deportiva y de ocio vinculada a las actividades marítimas y la agradable climatología), pero complementa la oferta en aras de romper con su estandarización y anclarla en valores y activos propios, locales, difícilmente exportables por otros destinos.

Existe un consenso generalizado en la literatura especializada sobre que en un contexto posmoderno los turistas presentan nuevas expectativas y motivaciones y anhelan visitar lugares con identidad propia, alto grado de autenticidad y diversidad de los recursos y actividades de ocio y recreativas (Scaramanga, 2012; Navalón 


\section{DEBILIDADES}

- Limitado desarrollo de productos turisticos innovadores y diversificados

Estacionalización de los recursos turisticos patrimoniales y medioambientales

Escaso número de Operadores Turísticos y Guias de

- Turismo con ofertas relativas a Patrimonio Cultural o Ambiental.

Catálogo de Protección de los bienes de interés cultural y de los bienes de relevancia local (PGOU) desactualizado (2009)

Ausencia de una oficina técnica municipal de Arqueologia y de un sistema de gestión del patrimonio

Escaso desarrollo de un modelo de gestión turistica y patrimonial integrado, inteligente e interdisciplinar por parte de la Administración Pública.

\section{DEBILIDADES}

El interés en aspectos culturales y naturales expresado por la población local y visitante (Plan Ciudad Santapolavant 2019, Plan Director del Turismo Inteligente de Santa Pola 2020) se encuentra entre las primeras posiciones en ambos estudios.

- Patrimonio natural excepcional con variados recursos medioambientales como el Parque natural de la Comunitat Valenciana "Les Salines de Santa Pola numeroso Patrimonio Cultural Inmueble que además abarca desde la Prehistoria hasta la actualidad

El $73 \%$ del territorio del municipio se encuentra protegido

Destino turistico nacional de primer orden. Incipiente destino turístico vacacional internacional

- La Sede Principal del Museo del Mar se ubica en el centro urbano del municipio ocupando el núcleo originario e irradiador de su urbanismo: El Castillo-Fortaleza de Santa Pola . La Sala Externa Portus Ilicitanus (BIC) se encuentra dentro del núcleo urbano de Santa Pola y junto a la principal vía de comunicación del municipio (Ctra. Elche-Santa Pola)

- Mayoria de recursos turisticos accesibles y/o practicables (2 playas, Acuario Municipal, Museo del Mar, la Lonja y el Parque Natural de Salinas )

- Red de rutas a pie y en bicicleta en el municipio reconocidas por la administración, publicadas y afianzadas.

- Los recursos patrimoniales de Santa Pola se adscriben a itinerarios culturales que complementa la comprensión de sitios arqueológicos vecinos ( el Portus llicitanus era dependiente de la Colonia Iulia Ilici Augusta situada $\mathrm{en} \mathrm{el}$ actual Parque Arqueológico L'Aleúdia de Elehe); forman parte de conjuntos tipológicos de entidad provincial y autonómica (Torres y fortalezas costeras del siglo XVI): y parte de su patrimonio inmaterial se comparte con el municipio vecino de Elche (Romeria Venida de la Virgen desde la Playa del Tamarit a Elche cada 28 de diciembre

- Santa Pola dispone de recursos museisticos especializados y sin competidores cercanos : el Barco Pesquero Esteban González y el Acuario Marino Municipal

\section{AMENAZAS}

neciente crisis sanitaria y socioeconómica provocada por la pandemia COVID-19

E Crisis económica glohal

- Catástrofes naturales agravadas por el cambio climático

a Progresiva degradación del estado de conservación de bienes que conforman el Patrimonio Cultural de Santa Pola

- Agotamiento de los destinos turísticos tradicionales por el auge de otros destinos competidores de Santa Pola que depende, principalmente, del Pais Vasco y de Elche

E Estructura del sol y playa masiva basada en turismo residencial con necesidad de reconversión para su adaptación a los nuevos parámetros turísticos

\section{AMENAZAS}

D Dar a conocer y poner en valor los recursos naturales y patrimoniales, usando los recursos antrópicos coherentemente para que no desaparezca el medio natural, recuperando, por ejemplo, la Sierra y su equilibrio ecológico.

口 Diversificar la economia, ampliando recursos para actividades que generen gasto en la población y que promueva la creación de nuevas empresas, aumentando y potenciando las áreas comerciales. creando una oferta diferenciada y de marca Santa Pola.

E Educar a la población desde la infancia (colegio) en el conocimiento de nuestro patrimonio

므 Creación en el Ayuntamiento de una estrategia transversal para implantar modelos de gestión de la información reutilizable y evitar los departamentos estancos entre las distintas áreas de gestión municipal.

apoyo y colaboración de la administración con las empresas turisticas locales.

口 Líneas de financiación europea, nacional y regional para la potenciación de los Destinos turisticos inteligente y para la puesta en valor del patrimonio

INFORMACIÓN QUE PROVIENE DEL PLAN DE CIUDAD SANTAPOLAAVANT (2019)

APORTACIONES PROPIAS DEL EQUIPO REDACTOR DE LA COMUNICACIÓN

INFORMACIÓN QUE PROVIENE DEL. PLAN DESTINO TURISTICO INTELIGENTE (2020)

Fuente: elaboración propia a partir de Ayuntamiento de Santa Pola y Sien Consulting (2020). Plan Director Destino Turístico Inteligente Santa Pola y Ayuntamiento de Santa Pola (2019). Plan Estratégico de Ciudad Santa Pola Avant. 


\begin{tabular}{|c|c|c|}
\hline & FORTALEZAS & DEBILIDADES \\
\hline OPORTUNIDADES & $\begin{array}{l}\text { Valorizar Patrimonio cultural y natural } \\
\text { de gran valor para diversificar destino } \\
\text { turistico consolidado a nivel nacional } \\
\text { Mejorar e intensificar la divulgación } \\
\text { preventiva y la estrategia relacional y } \\
\text { comunicacional hacia los públicos } \\
\text { internos y externos }\end{array}$ & $\begin{array}{l}\text { Crear un sistema integrado de gestión } \\
\text { del destino y de los productos turisticos } \\
\text { del destino. } \\
\text { Establecer un sistema de información de } \\
\text { marketing para el destino. } \\
\text { Integrar todos los planes y proyectos } \\
\text { estratégicos de gestión (ciudad, destino, } \\
\text { patrimonio) }\end{array}$ \\
\hline & FORTALEZAS & DEBILIDADES \\
\hline AMENAZAS & $\begin{array}{l}\text { Valorizar activos patrimoniales desde la } \\
\text { sostenibilidad económica, ecológica y } \\
\text { social }\end{array}$ & $\begin{array}{l}\text { Innovar en producto turistico } \\
\text { Gestionar integra e inteligentemente el } \\
\text { destino }\end{array}$ \\
\hline
\end{tabular}

Fuente: elaboración propia.

y Rico, 2016; Rico y Baños, 2016). Por tanto, la valorización de activos singulares, encaminada a potenciar la autenticidad del destino, resulta especialmente útil para esta estrategia de diversificación, siempre y cuando la puesta en valor de esos activos se oriente a las características de los mercados, sus valores y sus estilos de vida. En este sentido, como indica Rico (2014. p. 413) para el caso de destinos de la Costa Blanca, como Santa Pola, «la incorporación del patrimonio cultural como parte de la oferta turística contribuiría a dotar de mayor valor ańadido al destino y al mismo tiempo, daría respuesta a los requerimientos de cierta parte de la demanda turística» recalcando que el producto turístico patrimonial debe entrar en diálogo y complementariedad al producto principal vinculado, desde los orígenes del destino a las actividades marítimas (balnearias o recreativo-deportivas). En la misma dirección, tanto Martínez y Nicolás (2014) como Hernández, Duarte y Folgado (2018), apuntan a la importancia, para la generación de recuerdo, identificación o reconocimiento de los destinos turísticos, de asentar su estrategia o complementarla con procesos de puesta en valor y de interpretación del patrimonio. Apuntando en la misma dirección, Richards y Palmer (2010) destacan el papel del patrimonio y los eventos culturales de base identitaria local (hallmark events) en las estrategias de desarrollo local y reposicionamiento de los destinos turísticos maduros. Parece entonces haber cierto consenso en que la destrucción o banalización del paisaje cultural y la indiferenciación de la oferta responden a modelos que no atienden a las necesidades de los públicos característicos de una sociedad posmoderna (Muñoz, 2008). Como apuntan Rico y Navalón (2016) para el caso de la Costa Blanca, que existan recursos patrimoniales (Bienes de Interés Cultural, Bienes de Relevancia Local, Parajes Naturales, Parques Naturales, entre otras figuras de protección) no significa per se que se esté ofertando un producto turístico-cultural. Para ello, el destino ha de contar con un patrimonio lo suficientemente singular, atractivo y 
accesible que permita generar la oferta complementaria de servicios y equipamientos necesaria para convertir un activo patrimonial en un producto de turismo cultural. Estos nuevos productos permitirían atraer a los clásicos turistas culturales (aficionados o expertos con inquietudes culturales) y a la gran mayoría de los turistas que visitan un recurso patrimonial en un entorno litoral mediterráneo, los turistas vacacionales o culturales accidentales, que desean entretenimiento y enriquecer la estancia en el destino con experiencias singulares y ofertas de ocio adecuadas a sus necesidades e intereses. Para el caso de los destinos de la costa mediterránea, Pulido (2013, p. 228) apunta que

la cultura deviene en un atractivo cada vez más importante en la competitividad de los destinos turísticos de sol y playa. En las áreas maduras de las costas mediterráneas constituye una línea de actuación dentro de las estrategias generales de reestructuración del producto-destino [...]. Los visitantes potenciales no van a acudir a este tipo de destinos por su atractivo cultural. Sin embargo, la ausencia de elementos que posibiliten la realización de una serie de prácticas turístico-culturales va a repercutir negativamente en la imagen y competitividad de ese destino, susceptible de ser percibido como un lugar que no ofrece posibilidades y opciones de diferente tipo a un turista cada vez más activo.

Siendo absolutamente asumido por todos, el hecho de que la imagen de la Costa Blanca está asociada al turismo balneario, de sol y playa, en definitiva, no se trataría tanto de negar esta realidad o dejar de potenciarla, sino de reflexionar sobre los valores propios históricos y culturales, que pueden contribuir a diversificar la oferta turística santapolera en torno al mar Mediterráneo y a su esencia marítima y portuaria que deviene un continuo a lo largo de toda la historia comunitaria. Si hay un elemento territorial de carácter geográfico que ha condicionado el devenir de los acontecimientos históricos que se han dado en este trozo de tierra, en esta comunidad, ha sido y es el hecho de ser puerto de mar; la relación entre seres humanos, hombres y mujeres, la tierra y el mar, ha sido y es la fuerza motora de la historia local y de la herencia colectiva que ha producido como resultado tanto los elementos tangibles patrimoniales, muebles e inmuebles, que han llegado hasta nuestros días, como las costumbres, el habla, las tradiciones, las características gastronómicas propias, entre otros elementos patrimoniales intangibles. En ese sentido, «el patrimonio es un arma de identidad y, en definitiva, su singularidad contribuye a generar imagen de marca (mientras que) algunos destinos litorales se caracterizaron por mostrar una imagen homogeneizada, sin prácticamente ningún elemento de identidad propia» (Ballart y Juan, 2010, p. 206).

La generación de productos de turismo cultural y la estrategia de diversificación e innovación de la oferta del destino propuesta, resultado del Análisis DAFO y de las Estrategias FO-DO-FA-DA, requieren un enfoque claro de gestión. A continuación, se presenta el nuevo modelo de gobernanza del Museo del Mar de Santa Pola (museos y patrimonio cultural) basado en el modelo de museo-territorio e integrado en la filosofía que la marca destino Santa Pola, el Plan Director Destino Turístico Inteligente DTI Santa Pola (2020) y la normativa reguladora de los Museos y el Patrimonio de la Comunitat Valenciana, a partir de la creación de un 
Plan de Museo. Este Plan de Museo (para lo particular), junto con el Plan Director DTI Santa Pola, se convierten así en los cimientos para la creación de verdaderas herramientas de gobernanza del destino (Eshuis, Braun y Klijn, 2013).

NuEVOS MODELOS DE GESTIÓN PATRIMONIAL ENFOCADOS AL TURISMO CULTURAL, LA INNOVACIÓN Y EL DESARROLLO LOCAL: EL TERRITORIO-MUSEO

Cuando hablamos de territorio-museo o museo-territorio, partimos de una relación de conceptos que representan dos expresiones claras. Por un lado, está el museo, una institución cultural entre cuyas funciones no solo se encuentran las tareas de conservar, proteger y divulgar la cultura relacionada con aquellas colecciones que alberga, sino también la de crear identidad, formando parte de la oferta turística de un lugar determinado como activo en su desarrollo económico y, por lo tanto, creando ciudad. Por otro lado, el concepto de territorio cuya definición en este marco contextual engloba todos aquellos productos, resultado del paso del tiempo en un espacio geográfico específico, tangibles e intangibles, fruto de acciones antrópicas y de su transformación del entorno natural, que conforman el patrimonio colectivo de la sociedad local vinculada a dicho territorio y, por consiguiente, todo aquello que construye la memoria colectiva; de nuevo, su identidad.

En las últimas décadas el concepto de museo, su estructura y sus funciones han vivido una importante evolución tanto desde una perspectiva interna como desde la propia percepción que la sociedad tiene de ellos, que, con su demanda de productos culturales actualizados y competitivos, ha forzado esa transformación alejando al museo de su imagen clásica de espacio intelectual exclusivo, contenedor para la exposición de 'tesoros patrimoniales', convirtiéndolos en organismos abiertos y relacionales, democratizadores de la cultura y con una importante función social.

Esta nueva expresión también está presente en la fórmula de museo-territorio en la que el objeto a partir del cual se definen todas las estrategias de actuación es el territorio, es decir, toda la plataforma patrimonial de un espacio concreto y cuyo modelo de gestión debe estar al servicio de su comunidad, como describe Vicente i Guitart (2001, p. 30) al afirmar que

estos equipamientos (museos territorio) se definen y singularizan por la proximidad e implicación en su medio cultural-natural, por la vocación de uso comunitario basado en la participación ciudadana y por el tratamiento integral de los bienes patrimoniales de un espacio determinado, lo que se denomina el museo sin muros.

El territorio-museo nace a finales de los años 90 enmarcado en las nuevas estrategias de turismo y marca para el desarrollo local, ya que delimita un área espacial cohesionada no solo por sus agentes patrimoniales, históricos o naturales e inmateriales, sino también por aquellos conectores sociales que conforman la identidad local, como pueden ser la gastronomía o las actividades productivas, aspectos derivados de elementos también identitarios de esa sociedad, como es el caso del mar y la pesca para la localidad de Santa Pola. 
Las ideas clave de construcción del concepto de territorio-museo pueden resumirse como el desarrollo de una estrategia eficaz de musealización de un territorio que, además, contribuye al desarrollo sostenible del mismo. Este concepto se desarrolló en paralelo al de 'museo abierto' en el marco de un proyecto que tuvo como principal misión crear herramientas de gestión desde una visión territorial y con un doble objetivo: su uso social y el desarrollo local (Miró, 2009).

El objeto de gestión del territorio-museo va más allá del museo tradicional entendido como colección museográfica -tanto expositiva como en depósito- delimitada por cuatro paredes; la fórmula engloba un enorme espacio en el que se debe intervenir, incidiendo en todo el municipio a través de una red bien definida y articulada, que además se inserte en las estrategias y planes de desarrollo turístico de la localidad, tal y como definen Izquierdo et al. al explicar que «la metodología del territorio museo es una estrategia para la inserción del patrimonio en las políticas de planificación y desarrollo territorial, haciendo especial énfasis en la sostenibilidad y en la realización de nuevas propuestas orientadas a potenciar el turismo cultural» (2005, p. 36); una herramienta de gestión basada en estrategias pluridisciplinares que construyen un modelo interpretativo común a toda la plataforma patrimonial del municipio, creando un conjunto cultural interdependiente, sostenible y centralizado. Estrategias, además, con un alto grado de dinamización, ya que responden a necesidades específicas de cada territorio y, dentro de este, a las de cada elemento patrimonial, superando las propuestas tradicionales que se han llevado a cabo en las últimas décadas.

El éxito del modelo del territorio-museo, por lo tanto, debe basarse en el principio de planificación global, partiendo de un análisis de todo el tejido cultural de la localidad que permita definir sus potencialidades y necesidades para trazar una estrategia de actuación por fases que establezca urgencias y prioridades. En cuanto a su estructura orgánica y su funcionamiento, se hace necesaria la existencia de un organismo o equipo técnico coordinador de todas las áreas que administran los elementos conformadores de la plataforma patrimonial, coordinada con el resto de agentes turísticos locales, poniendo fin a la desarticulación de las partes que construyen la identidad de marca territorio y destino y dejando de lado las poco efectivas acciones sectoriales.

CONSTRUYENDO EL TERRITORIO-MUSEO: UN NUEVO MODELO DE GESTIÓN PARA EL Museo del Mar de Santa Pola integrado en el destino

En los últimos años nos hemos visto inmersos en una realidad administrativa relativamente rígida en lo que se refiere a museos, entendidos siempre como patrimonio cultural expuesto entre cuatro paredes, reformulado en los centros de interpretación o en los inmuebles históricos accesibles, pero con leves mejoras en términos socioeconómicos. Sin embargo, esta propuesta de territorio-museo para Santa Pola plantea una puesta en valor del patrimonio dentro de un modelo de desarrollo sostenible, analizando los recursos patrimoniales para una explotación más dinámica, racional, inteligente y siempre respetuosa, dentro de una estrategia inte- 
grada en el desarrollo local y turístico del municipio, creando una red de lugares de la memoria entendidos como partes de un oferta turística compleja y englobadas bajo la promesa de valor de la marca destino estratégicamente organizada y gestionada (De San Eugenio, 2011).

La proposición del modelo de gestión de territorio-museo en Santa Pola surge en el desarrollo del Plan Museológico del Museo del Mar, un documento encargado de racionalizar todos los aspectos, tanto internos como externos, relacionados con esta institución, a partir de una definición de su estado actual y un análisis de sus valores y necesidades de actuación para la optimización de su funcionamiento. Este análisis de las particularidades del museo y de la localidad fructificó en la elaboración de un modelo de nuevas relaciones institucionales, políticas y administrativas, para la construcción del futuro Territorio Museo del Mar de Santa Pola, culminando en la propuesta de creación de una comisión técnica municipal de patrimonio de carácter técnico multidisciplinar y con un claro enfoque hacia la generación de nuevos productos turísticos o la innovación y gestión coordinada de los ya existentes.

Esta comisión debe constituirse por todos aquellos agentes responsables de administrar los conjuntos de bienes arqueológicos, monumentales y naturales que construyen la plataforma patrimonial de la localidad; esto es, en primera instancia, por los técnicos competentes en materia de cultura, patrimonio y museos representados por la figura técnica del director/a del Museo del Mar, un técnico representante de Conselleria de Cultura especialista en la gestión del patrimonio y un técnico en arqueología, un técnico del Ârea de Urbanismo/Arquitectura y un técnico en medio ambiente. La planificación de actuaciones derivada de esta gestión deberá integrarse en las estrategias de desarrollo turístico local de la mano de un técnico del Área de Turismo. Además, para el diseño de estrategias comunes se debe incorporar, cuando el conjunto a intervenir lo haga necesario o según la naturaleza de las acciones, de un técnico del Archivo Histórico, un técnico del Área Jurídica o de un técnico de la Agencia de Desarrollo Local.

El Territorio Museo del Mar de Santa Pola se presenta como un gran museo abierto en continuo crecimiento y adaptación, integrado en el resto de ofertas turísticas de la localidad y con la participación de la sociedad, que estaría conformado por una red de itinerarios interrelacionados, cuya unidad de intervención es todo el territorio y englobando, con carácter fundamental, la consideración del paisaje y del desarrollo sostenible de dicha fórmula (Bringas y Vico, 2020). Estas redes de itinerarios se basan en la coordinación e interdependencia, comportándose como salas externas de la sede central del Museo del Mar como catalizador de todo este patrimonio y su gestión en su ubicación del Castillo-Fortaleza de Santa Pola. Actualmente el museo ya gestiona dos salas externas, como son el Portus Ilicitanus y el Barco Pesquero Esteban González. Tras el análisis del resto de recursos patrimoniales de la localidad, se desarrolla, en el apartado siguiente, una estructura de propuestas a llevar a cabo.

El consenso y planificación centralizada para la gestión territorial del patrimonio cultural de la localidad garantizaría el fin de la desvertebración de esta gestión. La propuesta de la nueva fórmula territorio museo plantea un plan territorial, 


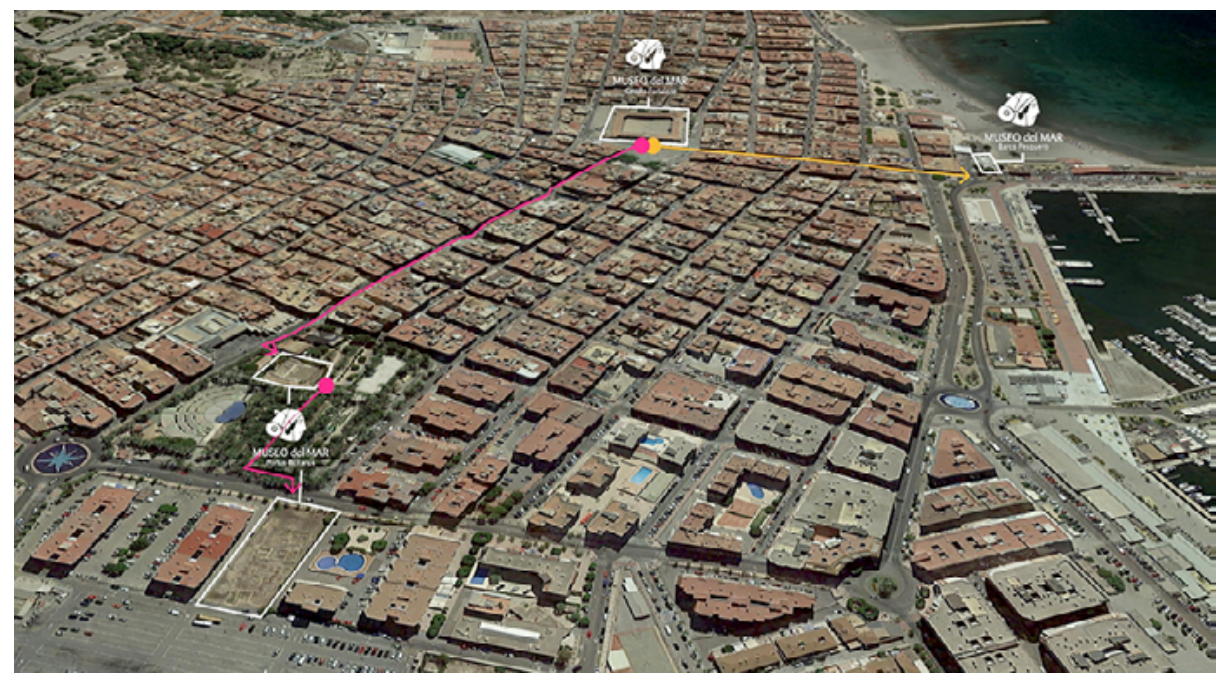

Figura 2. Sede central ubicada en el Castillo-Fortaleza y salas externas del Museo del Mar etnográficas (Barco Pesquero) y arqueológicas (Portus Ilicitanus).

Fuente: elaboración propia.

liderado por el Museo del Mar con una definición clara de su misión, objetivos y políticas internas, que incluye una red de bienes protegidos articulada bajo su estructura, con una enumeración de acciones a acometer organizadas y jerarquizadas en base al cumplimiento de las leyes de protección patrimonial y al valor y retorno de las inversiones en patrimonio, además de la rentabilidad resultante de su propio funcionamiento y sostenibilidad futuras (Go y Trunfio, 2012).

La creación de esta plataforma de redes multitemáticas o integradoras de todo el patrimonio que participa de su construcción favorecería la consolidación de la identidad de marca territorio, diversificando la oferta del destino de sol y playa y contribuyendo a la desestacionalización. Una identidad de marca territorio construida a partir de una oferta cultural que sitúa a su población como protagonista beneficiaria de esta fórmula de gestión, pero a su vez se erige como una experiencia de calidad para el visitante (Izquierdo et al., 2005), como también defiende Vicente i Guitart (2001, p. 31) cuando dice que

los museos de territorio representan un modelo de centro cultural basado en la proximidad a los intereses y motivaciones de sus ciudadanos y en la utilidad que pueden tener para su comunidad. Los museos de territorio deben ser útiles social y culturalmente.

La fórmula de gestión cultural de territorio museo solo es posible a través de la conjunción de varios factores como son la población local, el conjunto patrimonial y el entorno natural (Kavaratzis y Kalandides, 2015). Es a partir de esta inte- 
gración cuando se consigue reforzar la identidad de la marca territorio y destino y el compromiso y sensibilización de la población a la que representa e identifica. Potenciar estos valores identitarios implica, además, una necesaria voluntad política y administrativa que debe conformar una organización multidisciplinar, responsable de definir los planes y estrategias que deriven en el desarrollo local del territorio a partir de la transformación de su oferta turística.

En definitiva, la correcta construcción y desarrollo del territorio-museo se define en una serie de resultados clave como son:

- Una gestión más eficaz, global y centralizada, de todo el patrimonio del municipio a partir de estrategias de planificación unificadas, dando fin a la desvertebración de la oferta cultural de la localidad.

- Un modelo basado en un sistema de redes interdependientes, terminando con la rigidez de la museología tradicional y aplicando fórmulas dinámicas, efectivas y económicamente más sostenibles.

- El fortalecimiento de valores identitarios a partir de un marco interpretativo común para toda la plataforma patrimonial, pero que también integre a la población local y sus intereses, además del resto de agentes que construyen la oferta turística, favoreciendo actuaciones colectivas y no sectoriales (Braun, Kavaratzis y Zenker, 2013).

- La definición de estrategias integradas en el desarrollo económico local, construyendo así una oferta turística más competitiva y contribuyendo al fortalecimiento de la marca destino.

Como se ha indicado anteriormente, para construir desde una perspectiva científica el Museo del Mar como museo-territorio, resulta clave identificar los bienes patrimoniales que pueden ser fuente de generación de producto de turismo cultural en Santa Pola (naturaleza, nivel de conservación equipamientos y accesibilidad) (Navalón y Rico, 2016).

Construyendo El TERritorio-MUSEO: PORTFOLIO DE PRODUCTOS CULTURALES CON ALTA POTENCIALIDAD PARA LA CREACIÓN DE PRODUCTO TURÍSTICO CULTURAL INNOVADOR

Una de las particularidades más llamativas que se aprecian cuando se estudia el territorio de Santa Pola es el hecho de la existencia de amplios espacios naturales -que se extienden por más de $40 \mathrm{~km}^{2}$ de los $58,6 \mathrm{~km}^{2}$ totales del término-que ocupan cerca del $70 \%$ de la geografía del término municipal. Estos espacios de marcada relevancia ecológica -local e internacional-, con diferentes grados de protección y entre los que figuran territorios declarados como Parque Natural, Paraje Natural Municipal, Microrreservas y montes declarados de Utilidad Pública, son, principalmente, las áreas del Parque Natural de las Salinas de Santa Pola, de la Sierra y Cabo de Santa Pola y de la zona conformada por el sistema dunar y la microrreserva de la playa del Pinet. 
Dada su notable extensión, en estos entornos de especial relevancia natural es donde encontramos un mayor porcentaje de bienes inmuebles histórico-culturales presentes entre sus límites. Además, estos territorios son el escenario para el desarrollo de manifestaciones culturales inmateriales de diversa tipología como romerías o procesiones y de manifestaciones etnográficas propias de las actividades económicas tradicionales de pesca, explotación salinera y agricultura tradicional. En cuanto al número de estos bienes culturales inmuebles, el Inventario General del Patrimonio Cultural Valenciano (IGPCV) y el Catálogo de Protecciones del Plan de Ordenación Urbana de Santa Pola (PGOU 2009) recogen actualmente, y a la espera de la tramitación del documento recientemente actualizado en la anualidad 2022, un total de 5 Bienes de Interés Cultural (BIC) y un total de 43 Bienes de Relevancia Local (BRL), a los que pueden sumarse en torno a la docena de manifestaciones culturales materiales e inmateriales procedentes de otros inventarios no incluidos en el IGPCV, que de igual modo han de ser tenidas en consideración como recursos para crear nuevos productos turístico-culturales. Junto con la red de recursos patrimoniales dispersos por la geografía aparece una red de instalaciones museísticas especializadas en la didáctica y difusión del patrimonio histórico, arqueológico y etnográfico de Santa Pola que tiene al Museo del Mar, ubicado en el Castillo-Fortaleza de Santa Pola, como núcleo principal centrado en la divulgación de la historia, arqueología y etnografía de Santa Pola junto con sus dos subsedes formadas por el Museo Portus Ilicitanus como parque arqueológico, y el Barco Pesquero Esteban González como recurso etnográfico especializado. Dedicados a la comprensión y divulgación del patrimonio natural, Santa Pola cuenta con el Museo de la Sal y Centro de Interpretación del Parque Natural de las Salinas de Santa Pola como recurso especializado en la divulgación del Parque Natural y la etnografía; el Acuario Municipal de Santa Pola como núcleo zoológico dedicado a la biodiversidad marina mediterránea; y el Centro de Investigación Marina de Santa Pola (CIMAR), dedicado al conocimiento y divulgación del entorno natural marino.

Parte del territorio descrito anteriormente cuenta ya con una red de rutas afianzadas y reconocidas con promoción turística que recorren el territorio y conectan entre sí los distintos recursos patrimoniales que lo jalonan. De modo particular, el Parque Natural de las Salinas cuenta con dos rutas locales denominadas como Ruta Playa del Tamarit y Ruta Playa del Pinet y en el entorno de la Sierra y Cabo de Santa Pola encontramos cinco rutas senderistas formadas por cuatro itinerarios con reconocimiento local denominadas como Ruta de les Fortaleses, Ruta de Les Escaletes, Ruta del Salt y Ruta de la Sierra; y una ruta homologada por la Federació d'Esports de Muntanya i Escalada de la Comunitat Valenciana (PRV-CV 61Sierra de Santa Pola).

Con el objetivo de crear productos turístico-culturales, y una vez reconocido el territorio, se han enumerado todos los elementos presentes y se han integrado en conjuntos diferenciados entre sí conforme a su naturaleza tipológica para conocer la imagen global que presenta el municipio: instalaciones museísticas, yacimientos arqueológicos, torres y fortalezas de época moderna, arquitecturas militares de la Guerra Civil, edificios y elementos tipológicos tradicionales, arquitectura religiosa, entre otros, forman los distintos conjuntos que se distribuyen por la geografía del 

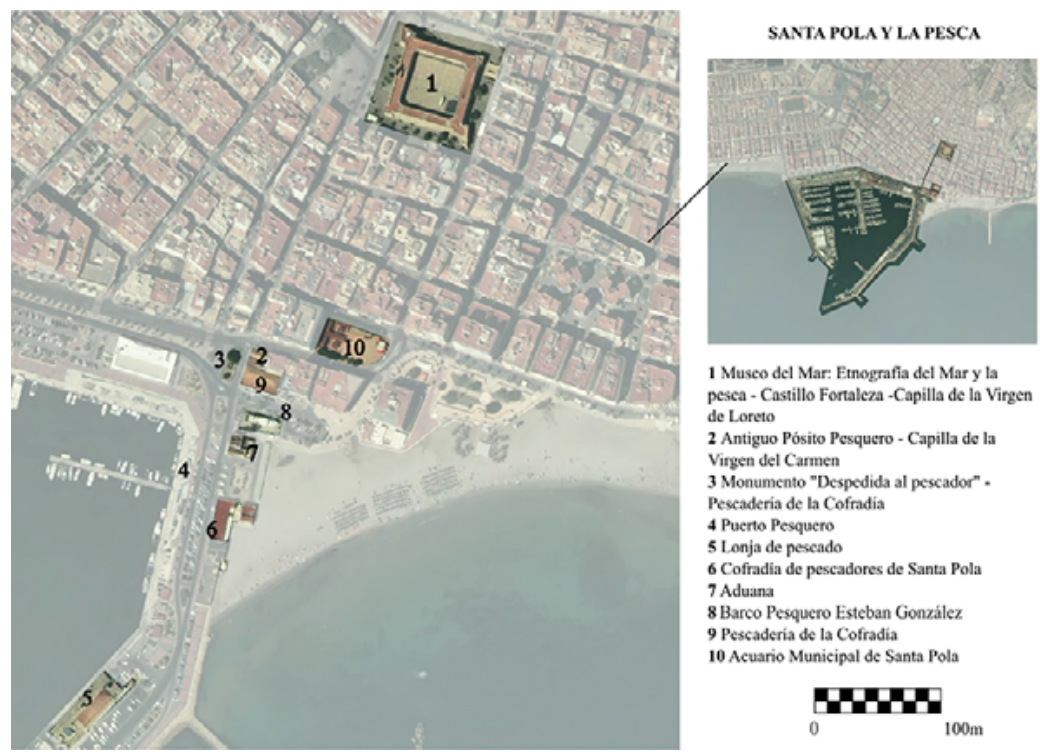

1 Museo del Mar: Etnografia del Mar y la pesea - Castillo Fortaleza - Capilla de la Virgen de Loreto

2 Antiguo Pósito Pesquero - Capilla de la Virgen del Carmen

3 Monumento "Despedida al pescador" . Pescaderia de la Cofradia 4 Puerto Pesquero

5 Lonja de pescado

6 Cofradia de pescadores de Santa Pola

7 Aduana

8 Barco Pesquero Esteban González

9 Pescaderia de la Cofradia

10 Acuario Municipal de Santa Pols

Figura 3. Activos para el itinerario cultural Santa Pola y la Pesca.

Fuente: elaboración propia.

municipio. A continuación, se han creado, desde una perspectiva temática ya enfocada en la creación del producto turístico cultural, los conjuntos de recursos para cada propuesta. Estos nuevos conjuntos están formados, en muchos casos, por recursos con distintas tipologías, pero que temáticamente integran un único grupo. De este modo, se construyen agrupaciones de recursos que, bajo la premisa temática que une los elementos que lo forman, aúnan recursos de distinta tipología como museos, arquitecturas religiosas, espacios naturales, elementos tipológicos tradicionales, entre otros. Posteriormente, se han analizado los elementos de cada conjunto en base al potencial que presentan como recurso turístico.

En la tabla 3, bajo estas líneas, se presenta una propuesta agrupada de conjuntos en función de una temática común, los recursos patrimoniales y museísticos vinculados a la propuesta, la relación del producto planteado con otro ya existente o de nueva creación y la potencial incorporación de nuevas tecnologías a la interpretación del patrimonio en el marco de la estrategia Santa Pola Destino Turístico Inteligente (DTI). Se destacan con indicador en verde las propuestas de proyectos para el desarrollo en un futuro próximo y con alto potencial turístico.

Para el análisis de cada recurso, se ha evaluado en primer lugar la relevancia cultural que representa y se ha estudiado su ubicación territorial para evaluar la relación que mantiene con cada elemento de su conjunto y con respecto a los demás recursos del resto de conjuntos, además de su estado de conservación y equipamientos de los que se dispone. De este modo, se establecen prioridades entre los elementos y se descartan los menos potenciales. 
TABLA III. PROPUESTA DE PRODUCTOS TURÍSTICOS CULTURALES TEMATIZADOS PARA SANTA POLA DESTINO

\begin{tabular}{|c|c|c|c|c|c|}
\hline ITINERARIO & ENTORNO & $\begin{array}{l}\text { RECURSOS } \\
\text { HISTÓRICO } \\
\text { PATRIMONIALES } \\
\text { Y ETNOGRÁFICOS }\end{array}$ & MUSEOS & $\begin{array}{l}\text { INTERACCIÓN } \\
\text { CON OTROS } \\
\text { ITINERARIOS }\end{array}$ & $\begin{array}{l}\text { ORIENTACION DESTINO } \\
\text { TURISTICO INTELIIGENTE. }\end{array}$ \\
\hline $\begin{array}{l}\text { SANTA } \\
\text { POLA } \\
\text { YLA } \\
\text { PESCA }\end{array}$ & $\begin{array}{l}\text { Núcleo urbano y } \\
\text { Puerto de Santa } \\
\text { Pola }\end{array}$ & $\begin{array}{l}\text { Capilla de la Virgen de Loreto } \\
\text { del Baluarte del Rey (BIC); } \\
\text { Antiguo posito pesquero; } \\
\text { Capilla de la Vingen del } \\
\text { Cammen, Monumento } \\
\text { "Despedida al peseador'; } \\
\text { Muelle y puerto pesquero de } \\
\text { Santa Pola; Aduana (BRL); } \\
\text { Lonja de pessado; Pescaderia } \\
\text { de la Colradia. }\end{array}$ & $\begin{array}{l}\text { Museo del Mar y la } \\
\text { colección aEEtnografia } \\
\text { del Mar y la Pescan, } \\
\text { salas extemas del } \\
\text { Museo del Mar (Bareo } \\
\text { Pesquero Esteban } \\
\text { Gonzalez) y Acuario } \\
\text { Marino Municipal. }\end{array}$ & $\begin{array}{l}\text { Santa Pola y el Resguardo } \\
\text { de la Costa: Fortaleras y } \\
\text { tomes del siglo XVI; Santa } \\
\text { Pola Arqueologia: Portus } \\
\text { llicitanus. }\end{array}$ & $\begin{array}{l}\text { Proyeeto Futuro: } \\
\text { Desarollo de una aplicación de } \\
\text { Rcalidad Aumentada para cl } \\
\text { Barco Pesquero Estcban González }\end{array}$ \\
\hline $\begin{array}{l}\text { SANTA POLA } \\
\text { YEL } \\
\text { RESGUARDO } \\
\text { DE LA } \\
\text { COSTA: } \\
\text { FORTALEZA } \\
\text { XVIY } \\
\text { TORRES } \\
\text { VIGIA }\end{array}$ & $\begin{array}{l}\text { Entomo natural } \\
\text { de la Sierra y } \\
\text { Cabo de Santa } \\
\text { Pola; Parque } \\
\text { Natural de las } \\
\text { Salinas de Santa } \\
\text { Pola; zona del } \\
\text { sistema } \\
\text { dunary } \\
\text { micromeserva de } \\
\text { la Playa del Pinct }\end{array}$ & $\begin{array}{l}\text { Castillo-Fortaleza de Santa } \\
\text { Pola (BIC); Torne d'Esealetes } \\
\text { (BIC); Torre Atalayola (Faro } \\
\text { de Santa Pola) (BIC); Torre } \\
\text { del Tamanit (BIC); Torre del } \\
\text { Pinet (BIC) }\end{array}$ & $\begin{array}{l}\text { Museo del Mar y su } \\
\text { coloceión eHistoriay } \\
\text { Arqueologias y las } \\
\text { salas dedicadas a la } \\
\text { Torre del Port del } \\
\text { Cap de I'Aljub } \\
\text { (Puerto Medieval) }\end{array}$ & $\begin{array}{l}\text { Santa Pola y la Pessa; } \\
\text { Santa Pola y la ned } \\
\text { defiensiva de la Guema } \\
\text { Civi; Santa Pola y la } \\
\text { Tradición Salinera; Santa } \\
\text { Pola y el abastecimiento } \\
\text { de agua: Ruta de los } \\
\text { aljibes. }\end{array}$ & $\begin{array}{l}\text { Proyecto Futuro: } \\
\text { Desarrollo de una aplicación de } \\
\text { Realidad Aumentada pana ta Tome } \\
\text { Vigia de Fscaletes y del Tamarit. } \\
\text { Desamollo de una experiencia } \\
\text { gamificada e interactiva mediante } \\
\text { Realidad Aumentada e imágenes } \\
360^{\circ} \text { para el Castillo Fontaleza de } \\
\text { Santa Pola. } \\
\text { Desamollo de videojuegos y } \\
\text { experiencias de Escape Room } \\
\text { Virtual en el Castillo Fortaleza. }\end{array}$ \\
\hline $\begin{array}{l}\text { SANTA POLA } \\
\text { Y LA RED } \\
\text { DEFENSIVA } \\
\text { DE I.A } \\
\text { GUERRA } \\
\text { CIVIL. }\end{array}$ & $\begin{array}{l}\text { Entomo natural } \\
\text { de las Sicrray y } \\
\text { Cabo de Santa } \\
\text { Polas Parque } \\
\text { Natural de las } \\
\text { Salinas de Santa } \\
\text { Pola }\end{array}$ & 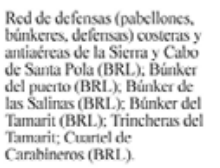 & $\begin{array}{l}\text { Proyecto Futuro: } \\
\text { Centro de } \\
\text { Imerpretación } 10^{\circ} \\
\text { Agrupación Sur de } \\
\text { Defensa de Costas }\end{array}$ & $\begin{array}{l}\text { Santa Pola y el Resguardo } \\
\text { de la Costa: Fortaleras y } \\
\text { torres del siglo XVl: } \\
\text { Santa Polay y la Tradición } \\
\text { Salinera, Santa Pola y el } \\
\text { abastecimiento de aguar: } \\
\text { Ruta de los aljibes. }\end{array}$ & $\begin{array}{l}\text { Proyecto Futuro: } \\
\text { Desarrollo de una aplicación de } \\
\text { Realidad Aumentada para la el } \\
\text { conjunto defensivo de la Guema } \\
\text { Civil. }\end{array}$ \\
\hline $\begin{array}{l}\text { SANTA POLA } \\
\text { ARQUEOLO- } \\
\text { GIA: PORTUS } \\
\text { ILICITANUS }\end{array}$ & $\begin{array}{l}\text { Entomo } \\
\text { urbano }\end{array}$ & $\begin{array}{l}\text { Zona arqueológica de la Picola } \\
\text { (BIC); Sala Extema Portus } \\
\text { llicitanus en Av. Portus } \\
\text { llicitanus(BIC); Domus } \\
\text { Romana del Palmeral (BIC); }\end{array}$ & $\begin{array}{l}\text { Museo del Mar y su } \\
\text { colección } \alpha \text { Histoniay } \\
\text { Anqueologian; Sata } \\
\text { Externa Portus llicitanus }\end{array}$ & Santa Pola y la Pesca & $\begin{array}{l}\text { Producto Virtualizado: Desamollo } \\
\text { de Realidad Aumentada para la } \\
\text { visita de la Casa Romana del } \\
\text { Palmeral }\end{array}$ \\
\hline $\begin{array}{l}\text { SANIA } \\
\text { POLAY EL } \\
\text { ABASTECI. } \\
\text { MIENTO DE } \\
\text { AGUA: } \\
\text { RUTA DE } \\
\text { LOS } \\
\text { ALIBES }\end{array}$ & $\begin{array}{l}\text { Entomo natural } \\
\text { de la Sicra y } \\
\text { Cabo de Santa } \\
\text { Pola }\end{array}$ & $\begin{array}{l}\text { Aljibes del Massapd (BRL); } \\
\text { Aljibe del Cuartel "Tore d'En } \\
\text { Mig"(BRL); } \\
\text { Aljibe del Maalo (BRL); } \\
\text { Aljibes del Faro (BRL); } \\
\text { Aljibe de la Torre de Escalcetes } \\
\text { (BRL); } \\
\text { Aljibe de las Perdices (BRL); } \\
\text { Aljibe de Calin (BRL); } \\
\text { Aljibes de los Pabellones del } \\
\text { Faro (BRL); } \\
\text { Aljibe de la familia Cuesta o de } \\
\text { Tomasin (BRL); } \\
\text { Aljibe del Salt (BRL);Aljibe } \\
\text { Tia Empar (BRL.), Aljibe del } \\
\text { Mereado de Viguetes }\end{array}$ & & $\begin{array}{l}\text { Sinta Pola y el } \\
\text { Resguardo de la Costa: } \\
\text { Fortalczas y tomes del } \\
\text { siglo XVI: Sunta Polay } \\
\text { la red defensiva de la } \\
\text { Guerra Civil }\end{array}$ & $\begin{array}{l}\text { Proyecto Futuro: } \\
\text { Desanollo de una aplicasión de } \\
\text { Realidad Aumentada para los } \\
\text { Alibers. }\end{array}$ \\
\hline
\end{tabular}

Fuente: elaboración propia. 

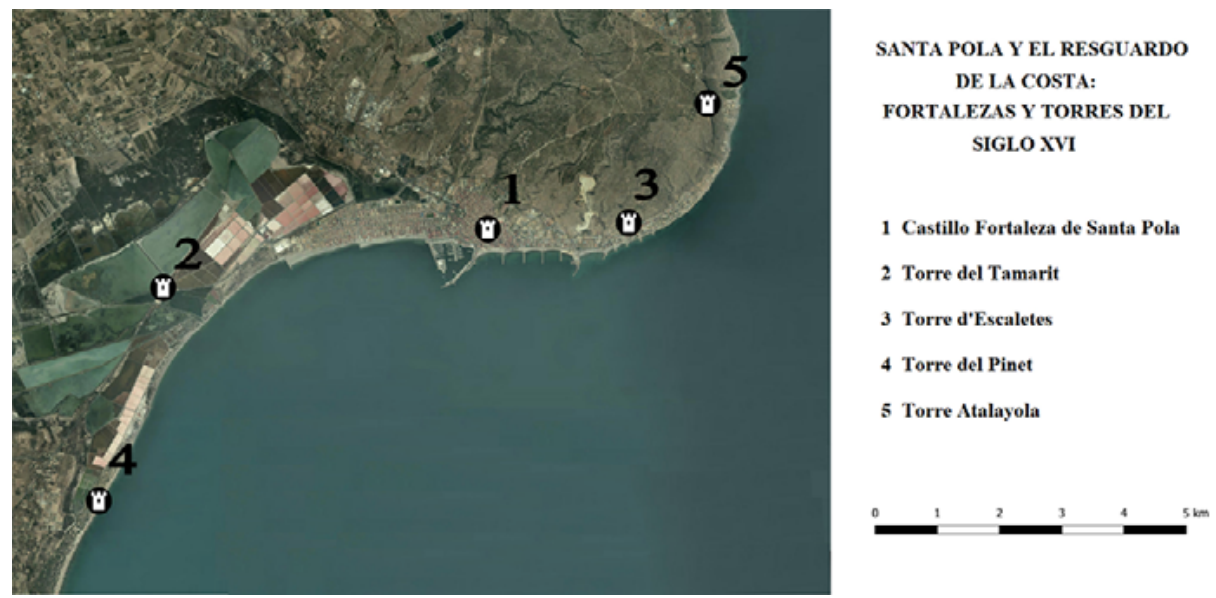

Figura 4. Activos para el itinerario cultural Fortaleza y Torres Vigía (Bien de Interés Cultural). Fuente: elaboración propia.

El resultado muestra que Santa Pola cuenta en su territorio con un amplio espectro, en cuanto a diversidad y número, de recursos naturales y culturales con potencial para constituir, en distinto grado de oportunidad, productos turístico-culturales diferenciados formados por la integración de los recursos en itinerarios de temática histórico-cultural-etnológica y entre los que pueden aparecer itinerarios, con el valor ańadido derivado de los espacios naturales de especial relevancia ecológica donde se desarrollan y que sirven como conectores espaciales entre productos turístico culturales y como reclamos turísticos en sí mismos. A continuación, se presenta de manera gráfica una serie de propuestas de productos turístico-culturales para Santa Pola bajo la forma de itinerarios temáticos creados a partir de la unión de los distintos recursos seleccionados para cada caso.

COMUNICANDO EL TERRITORIO-MUSEO: LA ESTRATEGIA DE COMUNICACIÓN REFLEJO DE LA ESTRATEGIA DE MARCA Y DE PRODUCTO

Para relatar gráficamente la promesa de valor del destino y siguiendo el desarrollo de los elementos sustanciales para la creación y el reposicionamiento de una marca destino apuntados por Lucarelli (2012), a continuación se presenta la familia de marcas puesta en marcha bajo la marca paraguas turística. Como resultado de los valores del destino, surge la grafía de la actual marca ciudad y destino de Santa Pola y, como consecuencia de ella, se genera la submarca Santa Pola Cultura, que a la vez respalda a la marca Museo del Mar y a las marcas producto de los distintos elementos patrimoniales musealizados (comercializados y comunicados bajo la marca Museo del Mar). En la actualidad, las marcas producto son el Museo del Mar Cas- 


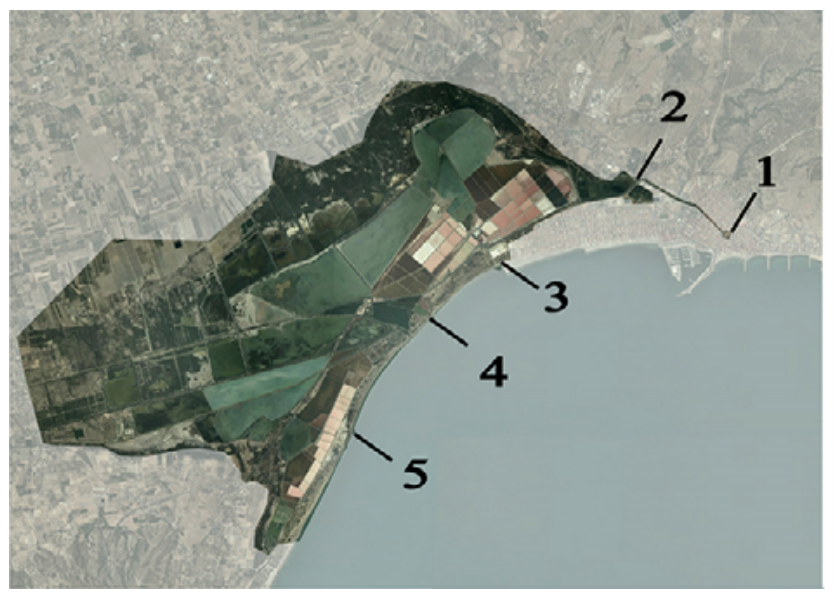

\section{SANTA POLA Y LA TRADICIÓN SALINERA}

\section{Museo del Mar \\ 2 Museo de la Sal}

3 Montañas de Sal - Embarcadero del Braç del Port - Gabarra

4 Gola de las Salinas

5 Salinas de Bonmatí

Figura 5. Activos para el itinerario cultural Santa Pola y la Sal (Bien de Interés Cultural y Parque Natural).

Fuente: elaboración propia.

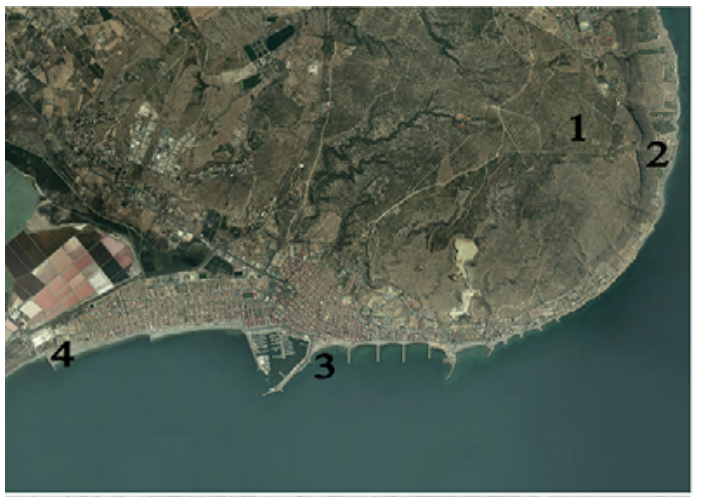

\section{SANTA POLA Y L.A RED DEFENSIVA}

DE LA GUERRA CIVIL

1 Red de defensas (pabellones, búnkeres, defensas)

costeras y antiaéreas de la Sierra y Cabo de Santa

Pola

2 Cuartel de Carabineros Torre d'en Mig

3 Búnker del Puerto

4 Búnker de Salinas, Búnker del Tamarit y trincheras del Tamarit

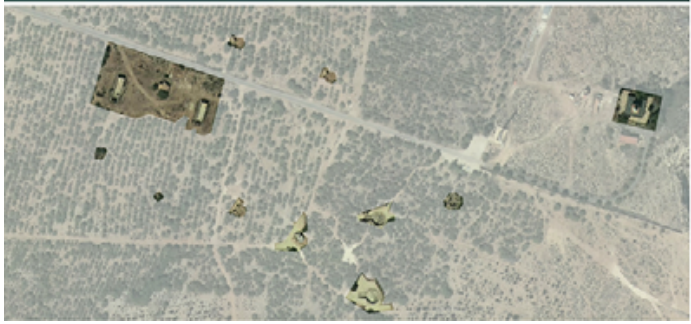

Figura 6. Activos para el itinerario cultural Santa Pola y su muro defensivo en la Guerra Civil (Bien de Relevancia Local).

Fuente: elaboración propia. 

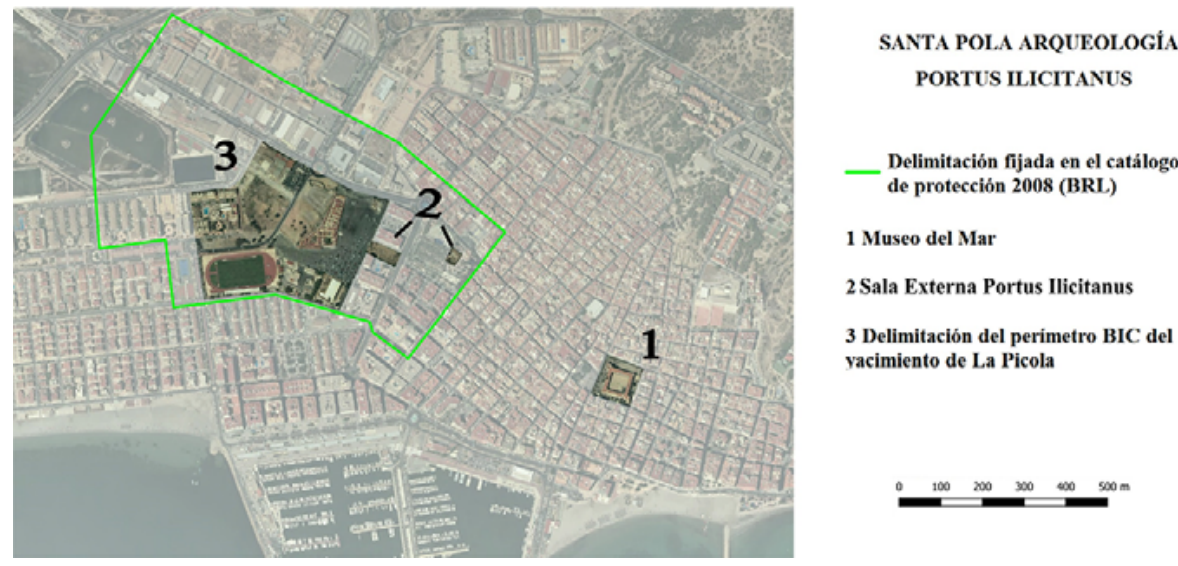

PORTUS ILICITANUS

_ Delimitación fijada en el catálogo

de protección 2008 (BRL)

1 Museo del Mar

2Sala Externa Portus Ilicitanus

3 Delimitación del perimetro $\mathrm{BIC}$ del yacimiento de La Picola

Figura 7. Santa Pola Íbera y Romana (Portus Ilicitanus) (Bien de Interés Cultural).

Fuente: elaboración propia.

tillo Fortaleza, Museo del Mar Barco Pesquero y Museo del Mar Portus Ilicitanus, con la posibilidad de ampliar este programa gráfico para cada uno de los productos turísticos interpretados y musealizados que se desarrollen en el futuro. Este diseño en forma de árbol, donde las marcas producto son respaldadas por la marca divisional (cultura) y la marca destino, es avalado por las principales aportaciones científicas realizadas por la academia en cuanto a la generación de arquitectura de marcas turísticas (Iversen, y Hem, 2008). Así se constata que las actividades de marketing turístico y patrimonial están muy alejadas de una acción limitadamente comunicacional o publicitaria y donde, muy al contrario, los desarrollos de branding son el resultado comunicacional de las estrategias de marketing (de producto) y de management (del modelo de gestión para el patrimonio y el destino).

Se plantea, por tanto, que el desarrollo gráfico contenga elementos identificativos de la marca destino oficial, creada precedentemente, y se diseñan dos versiones, una ampliada, que contiene el grafismo de olas del mar y la denominación Santa Pola para el caso de que la marca se reproduzca en solitario en los diferentes soportes de la comunicación off line y on line, y una versión simplificada para el supuesto en el que la marca producto aparezca respaldada por las marcas matriz destino (Santa Pola) o línea de productos (Museo del Mar) con el fin de no resultar redundantes gráficamente. En todo caso, se explicita la esencia marinera, portuaria y pesquera del territorio y su comunidad. Y para reforzar este mensaje, se incorpora la marca de calidad Peix de Santa Pola, creada por la Cofradía de Pescadores de Santa Pola con el respaldo municipal, en diálogo con las marcas producto especializadas en narrar la historia de la navegación y la esencia pesquera del municipio (la submarca Museo del Mar Barco Museo aparece comúnmente en diálogo con la marca Peix de Santa Pola en diferentes eventos e iniciativas). Conviene aclarar que la marca de calidad Peix de Santa Pola respalda las distintas iniciativas gastronómi- 


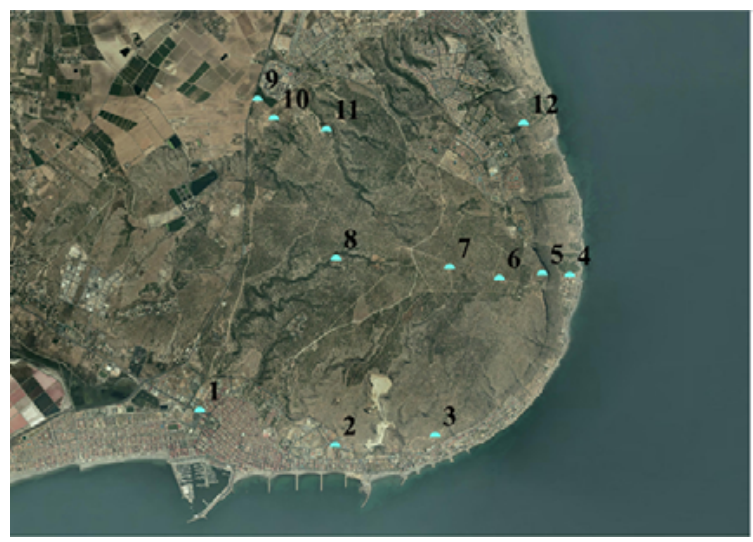

1 Aljibe del Mercado de Viguetes

2 Aljibes del Massapá

3 Aljibe de la Torre de Escaletes

4 Aljibe del Cuartel "Torre d'En Mig"

5 Aljibes del Faro

6 Aljibes de los Pabellones del Faro

7 Aljibe del Maño

8 Aljibe de Calin

9 Aljibe de las Perdices

10 Aljibe de la familia Cuesta o de Tomasin

11 Aljibe del Salt

12 Aljibe Tia Empar

Figura 8. Sala Pola y el agua (Bien de Interés Cultural).

Fuente: elaboración propia.

cas locales, la venta oficial del pescado, al por mayor y por menor, de la Cofradía de Pescadores y la creación de productos derivados de la pesca que se comercializan presencialmente en establecimientos locales homologados y digitalmente mediante distintas plataformas oficiales. De este modo, se construye, desde el liderazgo del sector público, una sólida arquitectura de marcas públicas en diálogo o cobranding con las marcas privadas, que resultan clave en la narrativa de la promesa de valor de Santa Pola, puerto comercial, de mar y de pesca, a lo largo de los siglos e importante ciudad marítima y puerto pesquero y destino balneario en la actualidad (Cerdá y Sarabia, 2016). En este sentido es necesario recalcar que

las marcas públicas y las marcas corporativas o las marcas producto pueden generar alianzas mutuas, o estrategias de cobranding, con el fin de intercambiar atributos positivos entre marcas que mejoren la imagen percibida por los públicos internos y externos que comparten [...]. El cobranding entre marcas estratégica orientada a compartir una misión y unos valores centrales y es, contemporáneamente, un pre-requisito para fortalecer alianzas en torno al destino. Las Marcas Denominación de Origen, las Marcas Agroalimentarias de Calidad, los clusters económicos e industriales del territorio y sus productos característicos, deben constituirse como componentes sustanciales en la estrategia de cobranding del destino (Cerdá, 2018, pp. 53-54).

Este enfoque, marketiniano y comunicacional, explicita un modelo de gobernanza propio y se constituye también como una potente herramienta relacional al servicio de la paradiplomacia y estrategias de internacionalización de la marca ciudad y destino. Como ventaja, este modo de articular la arquitectura de marcas permite desarrollar una identidad visual y un estilo comunicacional propio para cada producto que se desarrolle en el futuro, pero con un claro vínculo comunicacional con la promesa de valor del destino. 


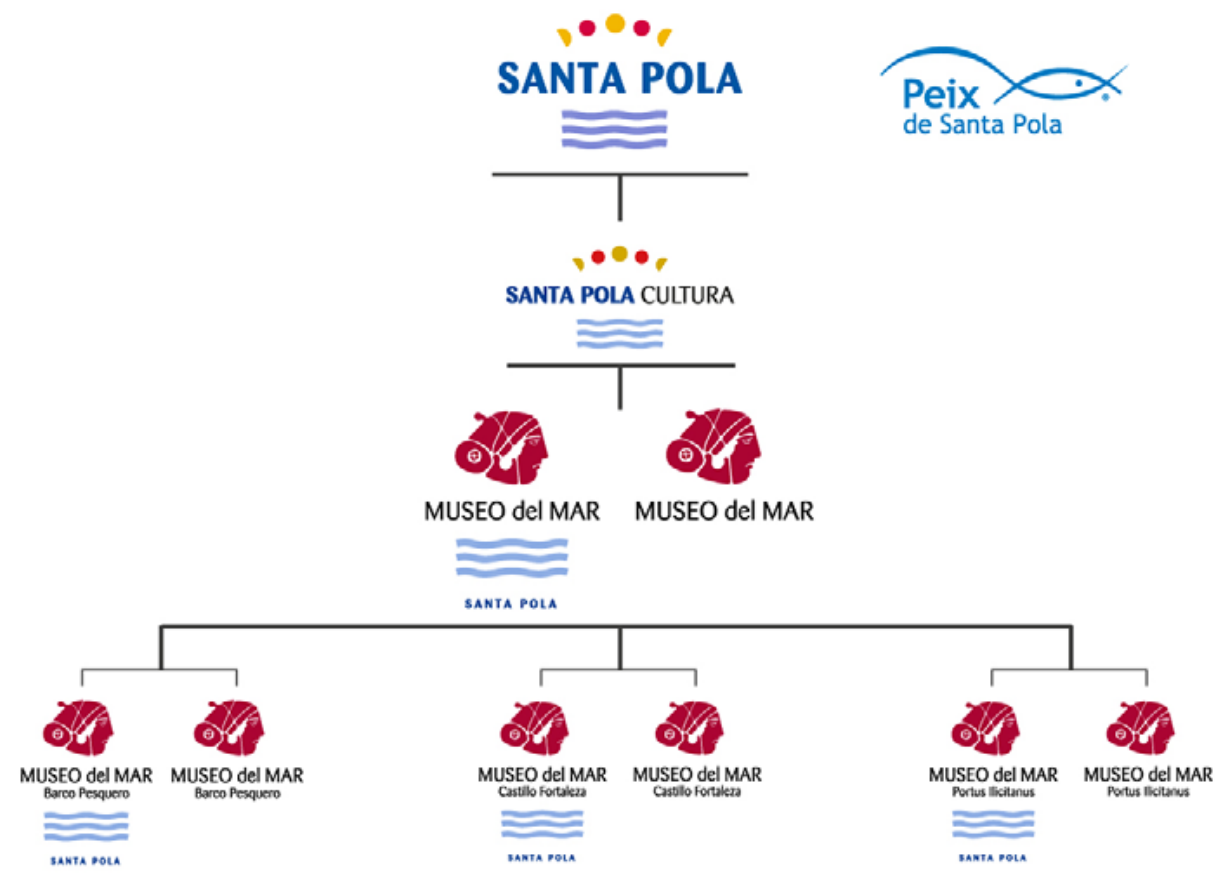

Figura 9. La arquitectura de marcas para los museos y el patrimonio de Santa Pola en relación con la marca destino.

Fuente: elaboración propia.

\section{CONSIDERACIONES FINALES}

Comenzábamos esta disertación incidiendo en la necesidad de que los enfoques de marketing y comunicación, a la hora de generar o reposicionar un destino, estuvieran integrados. Portfolio de productos congruente integrado bajo una sólida y distintiva promesa de valor del territorio y relato que enmarca, contextualiza y dota de sentido a todas las experiencias. Ambos son los dos pilares sobre los que asentar unas políticas públicas turísticas basadas en la evidencia, en el corpus científico que disciplinas como la sociología, la antropología, la geografía, el marketing o la comunicación, entre otras, aportan a los estudios turísticos. Para ello, se ha propuesto que el argumento principal del destino Santa Pola eleve su mirada y, encontrando el mar en su esencia, este aporte valores a la marca más allá de la práctica del turismo balneario de sol y playa y los deportes náuticos.

Ser puerto de mar, pesquero y comercial a lo largo de la historia es la promesa de valor sobre la que se propone un reposicionamiento de la marca destino Santa Pola. Esto permite ampliar la cartera de productos o experiencias turísticas e innovar sobre los ofrecimientos ya existentes. En este contexto, el patrimonio cul- 
tural se observa como un activo, en muchas ocasiones ocioso, o gestionado desde un enfoque poco integrado y con grandes posibilidades de gestión inteligente y de aplicación en su puesta en valor y comercialización de nuevas tecnologías. Junto a la detección y análisis de las potencialidades de desarrollo de productos turístico-culturales, se propone un nuevo modelo de gestión interdisciplinar que rebase los habituales compartimentos estancos que limitan una intervención integral y estratégica sobre el destino y su patrimonio. Además, estas políticas públicas han de ir acompañadas de una política pública de comunicación (no menos importante) que responda estratégicamente al modelo propuesto. De este modo, se plantea una arquitectura de marcas de respaldo para el destino integrada comunicacionalmente bajo el paraguas de la marca turística Santa Pola.

Muchos son los retos a los que se enfrentan las propuestas realizadas en este texto y que devienen líneas de investigación futura para el destino analizado. Es preciso estudiar en profundidad la imagen percibida y las expectativas hacia la marca de los diferentes públicos (internos y externos) con el fin de que cada desarrollo de producto responda a las necesidades planteadas por los stakeholders, segmentados en función de variables socio- y psicográficas. También será preciso mapear los agentes privados, empresariales o provenientes de la sociedad civil, que resultarán clave en el desarrollo de esta estrategia. De este modo, la estrategia propuesta necesita avanzar en el conocimiento de públicos internos y externos para que el enfoque sea participativo, relacional, sólido y útil para el desarrollo local.

En ese marco, los museos deben ser instituciones catalizadoras y jugar un papel activo en esta estrategia, verdaderos agentes turísticos enfocados a la conservación del patrimonio, la creación de experiencias turístico-patrimoniales, la potenciación de la imagen del destino y el desarrollo territorial. Suscribimos por tanto a Navalón y Rico (20, p. 283) cuando apunta que «en este contexto resulta obvio que los museos (en la Costa Blanca...) deben asumir un discurso menos erudito y más comprensible y atractivo, sin dejar de ser establecimientos de investigación que promuevan, además, la conservación del patrimonio». 


\section{BIBLIOGRAFÍA}

Ayuntamiento de Santa Pola y Sien Consulting (2020). Plan Director Destino Turístico Inteligente Santa Pola (inédito).

Ayuntamiento de Santa Pola (2019). Plan Estratégico de Ciudad Santa Pola Avant. https://www. santapolavant.es/images/files/documentos/documento-definitivo/Plan\%20Estrat\%C3\%A9gico\%20Santapolavant.pdf.

Baker, B. (2012) Destination Branding for Small Cities. The essentials for successful place branding. Total Destination Marketing.

Ballart Hernández, J. y Juan i Tesserras, J. (2010). Gestión del Patrimonio Cultural. Ariel Patrimonio.

Blain, C., Levy, S. Y Ritchie, B. (2005) Destination Branding: insights and practices from destination management organizations. Journal of Travel Research, (43), 328-338.

Boisen, M., Terlouw, K. y van Gorp, G. (2011). The selective nature of place branding and the layering of spatial identities. Journal of Place Management and Development, 4(2), 135-147.

Braun, E., Kavaratzis, M. y Zenker, S. (2013). My city-my brand: the different roles of residents in place branding. Journal of Place Management and Development, 6 (1), 18-28.

Bringas Heredia, A. y Vico Moreno, R. (2020). Aproximación al modelo de gestión de Territorio-museo a partir de casos prácticos. Universidad de Alcalá.

Cerdá Bertomeu, M.J. (2018). Arquitectura de Marcas Destino y cobranding de Marcas Turísticas: Enfoques de Gobernanza Territorial. ROTUR Revista de Ocio y Turismo, 12, 43-59.

Cerdá Bertomeu, M.J. y Sarabia Sánchez, F.J. (2016). Stakeholders' perceptions of place branding and the role of the public sector: An exploratory analysis. Place Branding and Public Diplomacy, doi:10.1057/s41254-016-0016-8.

Delgado Ruiz, M. (2000). Turismo y Cultura en un tiempo descoyuntado. Turismo cultural: el patrimonio histórico como fuente de riqueza. Fundación del Patrimonio Histórico de Castilla y León.

Eshuis, J., Braun, E. y Klijn, E.H. (2013). Place marketing as governance strategy: An assessment of obstacles in place marketing and their effects on attracting target groups. Public Administration Review, Vol. 73(3), 507-516.

Florek, M. y Insch, A. (2011). When Fit Matters: Leveraging Destination and Event Image Congruence. Journal of Hospitality Marketing \& Management, 20 (3-4), 265-286.

Giovanardi, M. (2012) Haft and sord factors in place branding: between functionalism and representationalism. Place Branding and Public Diplomacy, 8(1), 30-45.

Go, F y Trunfio, M. (2012). A paradigm shift from tourism destination management to democratic governance of place branding: the cases of Pompei and Campi Flegrei. Journal of Travel and Tourism Research, Special Issue Destination Management.

Govers, R. (2013). Why place branding is not about logos and slogans. Place Branding and Public Diplomacy, 9 (2), 71-75.

Hernández, J.M., Duarte, P.A. y Folgado, J.A. (2018). The contribution of cultural events to the formation of the cognitive and affective images of a tourist destination. Journal of Destination Marketing \& Management, 8, 170-178. 
Iversen, N.M. y Hem, L.E. (2008). Provenance associations as core values of place umbrella brands: A framework of characteristics. European Journal of Marketing, 42 (5/6), 603-626.

Izquierdo i Tugas, P., Juan i Tresserras, J. y Matamala Mellin, J.C. (coords.) (2005). Centros de Interpretación del Patrimonio. Manual Hicira. Diputación de Barcelona.

Kavaratzis, M. y Натсн, M.J. (2013). The dynamics of place brands: An identity-based approach to place branding theory. Marketing Theory, 13(1), 69-86.

Kavaratzis, M. y Kalandides, A. (2015). Rethinking the place brand: the interactive formation of place brands and the role of participatory place branding. Environment and Planning A, 47, 1368-1382.

Kerr, G. (2006) From destination brand to location brand. Journal of Brand Management, 13(4), 276-283.

Linchrou, M., O’Malley, L. y Patterson, M. (2008). Place-product or place narrative(s)? Perspectives in marketing of Tourism Destinations. Journal of Strategic Marketing, 16(2), 27-39.

LuCARELli, A. (2012). Unraveling the complexity of 'city brand equity' a three-dimensional framework. Journal of Place Management and Development, 5, 231-252.

Martínez, E. y Nicolás, M.A. (2014). The Construction of Tourist Space by Public Administration and Institutional Communication: The Image of the Brand Andalucía as a Tourist Destination. Journal of Promotion Management, 20 (2), 181-199.

Miró Alaix, M. (2009, 1 de julio). Museo abierto y territorio museo, nuevos conceptos para la interpretación territorial del patrimonio cultural (ponencia). Seminario «Planificación interpretativa y diseño de centros: primeros modelos", Sevilla.

Muñoz, F. (2008). Urbanalización. Paisajes comunes, lugares globales. Gustavo Gili.

Navalón García, R. y Rico Cánovas, E. (2016). Nuevas orientaciones en el desarrollo de productos de turismo cultural. El turismo en Alicante y la Costa Blanca, Canelobre, 66, 279-289.

Pulido Hernández, J.I. (coord.) (2013). Turismo cultural. Editorial Síntesis.

Richards, G. y Palmer, R. (2010). Eventful Cities. Cultural management and urban revitalisation. Routledge.

Rico Canovas, E. (2014). El patrimonio cultural como argumento para la renovación de destinos turísticos consolidados del litoral de la provincia de Alicante. Tesis doctoral. Universidad de Alicante.

Rico Cánovas, E. y Baños Castiñeira, C. (2016). El patrimonio cultural en los procesos de renovación de áreas turísticas litorales. Una aproximación al destino turístico de la Costa Blanca (Alicante, España), Cuadernos Geográficos, 55, 299-319.

Rico Canovas, E. y Navalón García, R. (2016). El patrimonio cultural: recursos y potencialidades para su desarrollo turístico. El turismo en Alicante y la Costa Blanca, Canelobre, 66, 109-123.

SAn Eugenio, J. (coord.) (2011). Manual de Comunicación Turística. De la información a la persuasión, de la promoción a la emoción. Documenta Universitaria.

San Eugenio, J., Nogué, J. y Govers, R. (2017). Visual landscape as a key element of place branding. Journal of Place Management and Development, 10, 23-44.

Scaramanga, M. (2012). Talking about arts. A theoretical framework clarifying the association between culture and place branding. Journal of Place Management and Development, 5(1), 70-80. 
Vicente i Guitart, C. (2001). Museos, patrimonio y territorio. B.MM. Cuaderno Central, n. ${ }^{\circ} 55$ (abril-junio), 29-31. Barcelona.

Zenker, S. y Braun, E. (2017). Questioning a «one size fits all» city brand: Developing a branded house strategy for place brand management. Journal of Place Management and Development, 10 (3), 270-287. 